\title{
10,000 Steps a Day for Health? User-based Evaluation of Wearable Activity Trackers
}

\author{
Aylin Ilhan \\ Heinrich Heine University \\ Düsseldorf, Germany \\ aylin.ilhan@hhu.de
}

\author{
Maria Henkel \\ Heinrich Heine University \\ Düsseldorf, Germany \\ maria.henkel@hhu.de
}

\begin{abstract}
We present the results of a survey on perceived service quality and service acceptance of activity trackers with a focus on country-based differences (US and Germany). The mutual influence of perceived service quality and service acceptance is being investigated. A new research focus based on activity trackers is the topic of medical health funds. Are users ready to share activity data with health insurance and expecting rewards in return? This study $(N=803)$ supplements previous research which is mainly based on small sample sizes or qualitative results. Our research model is based on the Information Service Evaluation (ISE) model which includes common models such as TAM and UTAUT. Results show that aspects such as Fun, Gamification, Impact and Usefulness are very important regarding activity tracker use. Furthermore, user's opinion on the support of medical healthcare funds and reducing medical fees is rather positive and significantly differentiates between US and German participants.
\end{abstract}

\section{Introduction}

2,000 steps yesterday, 4,000 steps today and maybe 8,000 steps tomorrow. How many steps did you do today? Nowadays, activity tracking, e.g., the counting of steps, is nothing unusual anymore. The demand for smart wearable products in the health care domain such as activity trackers, also known as actigraphs, is growing rapidly. About $80 \%$ market share is defined by basic wearables (e.g., Fitbit, Xiaomi, Garmin) and 20\% by smart watches (e.g., Apple Watch, Samsung, Gear, BBK) [10].

In today's age, the collection of individualized data through wearable sensors or other means of Information and Communication Technology (ICT) has potential for monitoring and improving citizen's health welfare: "Emerging persuasive technology and ubiquitous wearable sensors offer much promise for improving health and fitness practices" [9:487]. An activity tracker can have different functions, such as counting steps, active minutes, calories burned, distance covered or providing sleep analysis as well as measuring and documenting the heart rate, food intake and much more (Figure 1).

The possibility to be one's own administrator and account for one's own self-improvement through the functions of activity trackers (data collection or activity mining), is defined as self-quantification [7, 17]. Selfquantification is possible through a "system that helps people collect personally relevant information for the purpose of self-reflection and gaining self-knowledge" $[7: 2,17]$.

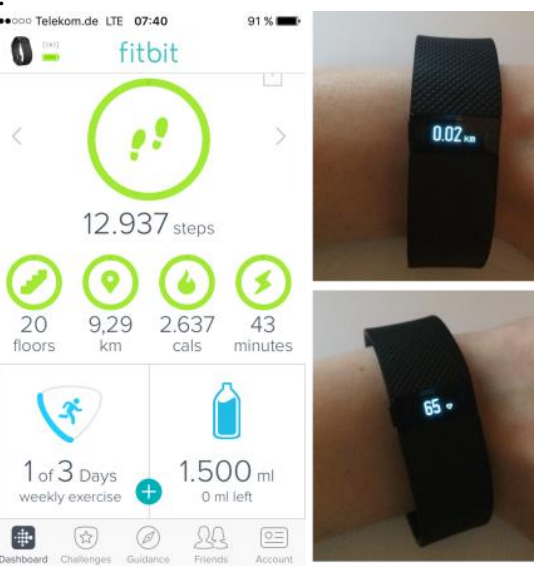

Figure 1. Fitbit app (left); Dis tance and heart rate $s$ hown on the tracker (right)

Indeed, users might want to observe and document their own fitness activity and health information [20], for self-reflection or self-improvement, but there might be other reasons as well. We would like to learn more about the "typical" activity tracker user and how people feel motivated to take care of their own health and fitness activity by using activity trackers. Beyond the fact that people could manage their own health and fitness level by wearing activity trackers, what about health insurance funds? Should they reward customers for documented activity and should health insurance 
funds even have access to collected fitness and health data to begin with?

The purpose of this empirical study is to find out more about the user experience by using information systems, here activity trackers, and the actual influence on their behavior. But how does the purpose of this study connect to similar research?

In a study by Fritz et al. [9], the results show that consumers of fitness tracking wearables use the collected data as feedback to change their activity behavior, by taking more steps. Furthermore, their participants confirm that the use of trackers evokes a physical addiction. Related to impact, participants also reported that the real-time awareness supports the improvement of activity. Therefore, real-time awareness might trigger an implicit durable behavior change [9]. Giddens et al. [13] conducted a study with 53 participants, and found that using an activity tracker has a positive impact on steps taken, which has a positive impact on wellbeing and health. They also found, however, that users reported increased wellbeing regardless of their step count and attributed this to the fact "that the device itself may raise awareness of one's physical activity and the importance of a healthy lifestyle that includes physical movement" [13:3632].

Different aspects of fitness and healthcare devices attract attention in the research domain. Some studies focus on the acceptance of healthcare wearable devices and reasons for the adoption of medical and fitness wearable technologies by using models such as UTAUT 2 and PMT for Chinese users [11]. Some concentrate on the discontinuance of using activity trackers [5]. Shin, Cheon, and Jarrahi [23:1] call attention to previous studies indicating that "such devices fail to deliver on health benefits in the long term" and that merely collecting data is not the key to success: "[D]ata provided by these technologies are not sufficient to motivate users, and other motivators are needed" [23:1]. This opinion is shared by Ledger and McCaffrey [16, 23], too. Furthermore, Angulo et al. [2] mentioned that activity trackers are characterized as a facilitator and not primary motivator.

Another study concentrating on user motivation conducts interviews with people using fitness tracking systems over a time interval [7]. But motivation may not be the only factor leading to success, i.e., a change in behavior and eventually the improvement of wellbeing. Other previously analyzed aspects are awareness, goals, and impact of such devices [9]. Shih et al. [22] show in their literature review which challenges and barriers are hidden in aspects of use and adoption of wearable activity trackers. Based on their review, they conducted a study with 26 undergraduate students to analyze the triggering factors. Alturki and Gay [1] focus on the impact of fitness IT services to analyze the triggering motivation. They point out that most studies concentrate on "feasibility or pilot studies and had small sample sizes" [1:203].

One topic, which is not solicited as widely in previous research, is the question of linking activity data to health insurance funds. Is it imaginable, that customers agree to health insurance funds having access to their fitness data, enabling discounts on health insurance contributions or rewards, by reaching a certain count of steps?

To gain further insight into these and similar issues, we created an online survey including many aspects that are based on findings of previous researchers.

It contributes to previous research in three ways:

First, we depict results on a big count of participants as most results concentrate on a small sample size up until now. This allows a conclusion based, among others, on the correlation among different aspects, which helps to understand the influence of activity trackers better. Results of this study could be compared to the previous findings.

Secondly, the survey is built with the aim to enable a country-specific evaluation of data, in this case, between Germany and the United States of America.

And thirdly, this study enables a contribution to a rather new research angle: health insurance funds. Could they be characterized as a motivator or demotivation related to the use of activity trackers?

\section{Theoretical Model Framework}

We based our questionnaire on the ISE model [21]. It combines different aspects of traditionally known models, such as the UTAUT [28], TAM [6], TAM 2 [27] and MATH [4] for a holistic evaluation of information systems. In respect to the study's purpose and scope, the perceived service quality and acceptance dimensions of the model are adapted and completed by taking a deeper look at the results and theory of previous research (Figure 2). To be more specific, the first dimension (D1) of the model concentrates on the user's perceived service quality of the activity tracker, based on Ease of Use, Usefulness, Trust, Fun and Gamification [21]. The factors Ease of Use and Usefulness are important, as, for example, success and acceptance of a service are, among others, dependent on them [27]. Does the user feel overwhelmed while using a system or is it easy to use with relatively little effort? In this study, Usefulness is characterized by the enhancement of fitness awareness and activity. Up until now, we define the following types of the indicator Usefulness for the purpose of our study:

- Improvement of fitness level,

- Improvement of health status. 
To confirm reliability, Cronbach's alpha $(\alpha)$ was calculated after the end of the survey to "determinate how much the items on a scale are measuring the same underlying dimension" [15]. The resulting value of .806 is adequate.

According to Gefen, Karahanna, and Straub [12], the factor Trust is an essential characteristic related to the quality of a service. Handling of activity data is not limited to counting calories or steps. Analyzing tracked data can result in very personal and sensitive health care information. Kawamoto et al. [14:107] show that with data collected by activity trackers, physical conditions such as "the subjective level of drunkenness, fever, and smoking cessation" can be detected. Therefore, tracked data is a good which should be handled and shared carefully while protecting individual privacy.

The Fun factor refers to intrinsic motivation external factors, such as appreciation do not have priority. It actually matters that participants do something just because it "is fun". This factor is a credit to Venkatesh [26] and is previously defined as perceived enjoyment. One way to further enjoyment of a system's usage is to gamify it. Therefore, the research model (Figure 2) includes the factor Gamification as it could be characterized as an extrinsic motivation factor. One study shows that 18 participants out of 30 point out "that system goals and rewards influenced on their personal activity and fitness goals" [9:492]. This kind of reward is a typical element of gamification. Gamification means "the use of game design elements in non-game contexts" [8:10]. Gamification in combination with fitness is "one of the most popular utilizations of gamification" [29:1]. Not only achievements and awards, but competitions between friends are typical game components that support the own motivation to fulfill individualized health goals [29].

The perceived service quality (D1) of an activity tracker is one aspect for evaluating an information system, its actual acceptance by the user community is another (D3). According to Schumann and Stock [21], the differentiation between the factors Adoption and Use is essential. One could use something only a limited time and never again (Opting-Out) or one could use something regularly. In our survey, we simplify this issue by asking whether a participant is currently using a tracker or has stopped using it and for what reason. If a service is being used, it could enhance the user during daily tasks, or even have direct influence on their behavior. This is described as Impact [21]. Up until now, we define the following types of Impact $(\alpha=.785)$ for the purpose of our study:

- Improvement of wellbeing,

- Addiction,

- Behavioral change.

In many cases activity trackers are seen as tools for raising awareness and for controlling one's own activity level. Reacting to this might result in a change of behavior and eventually in an improvement of wellbeing. A certain dependency or even addiction might not be unrealistic in such a case, as actions can turn into habits and finally compulsion [24].

The last factor is Diffusion. Our questionnaire covers different types of Diffusion for activity tracker usage and is therefore defined as:

- Dissemination,

- Contagion,

- Group pressure,

- Enforcement.

Users who are satisfied with their activity tracker might recommend or advertise it to their friends and colleagues actively (Dissemination) or passively (Contagion): "[A] superior or co-worker suggests that a particular system might be useful, a person may come to believe that it actually is useful, and in turn, form and intention to use it" [27:189]. Does someone only or at least initially use an activity tracker, because everyone in the family or their friends did (Group Pressure)?

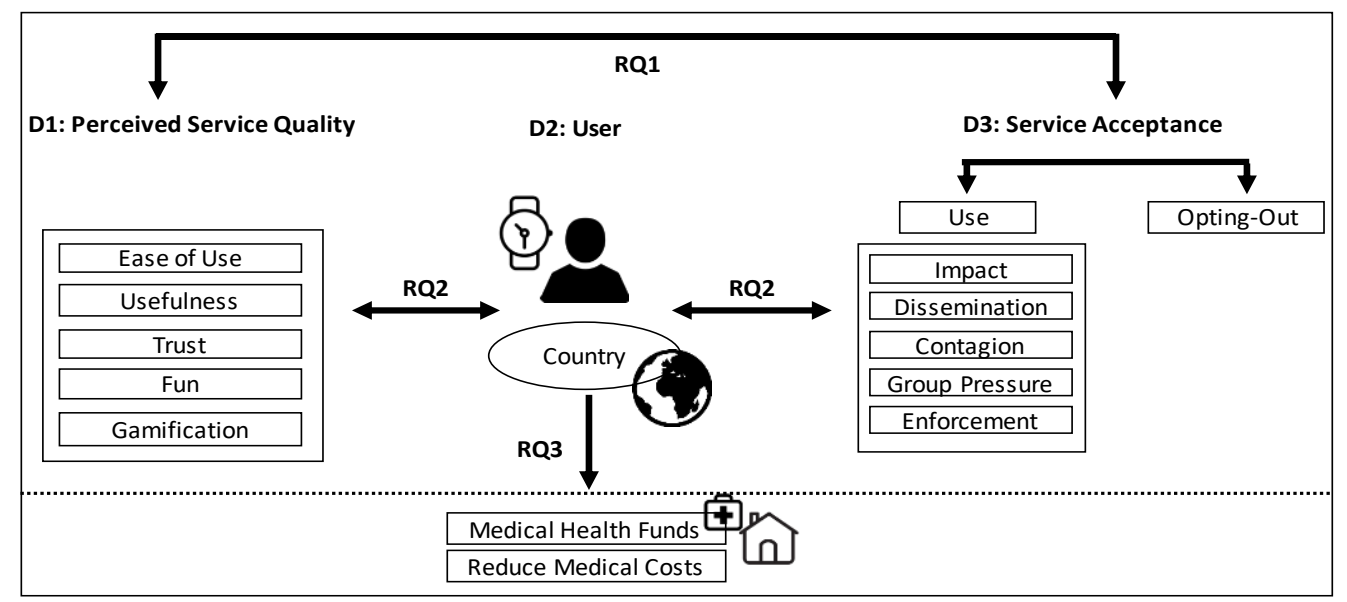

Figure 2. Our research model 
Is it even enforced at work or school, to use an activity tracker (Enforcement) as for example at Oral Roberts University in Tulsa, Oklahoma [25]? Two research questions (RQ1 and RQ2) are concentrating on these aspects to find out the strengths and weaknesses of trackers (RQ1a) and, by using the ISE model (RQ1b), to analyze the correlation between each item of perceived service quality and service acceptance:

RQ1a: What strengths and weaknesses are recognized by the participants (based on perceived service quality and acceptance) concerning activity trackers?

RQ1b: How do perceived service quality and acceptance of activity trackers influence each other?

At the center of the model, there are the users (D2) with their individual backgrounds. One purpose of the research is the differentiation between Germany and US.

RQ2: Do German participants' opinions differ from US participants', based on the agreement on perceived service quality and acceptance, regarding activity trackers?

Lastly, there is the question of the role of health insurance in the advent of actigraphy. Would a user still use an activity tracker if their insurance was eligible to examine the activity data? Or could it be a motivator to get rewards or discounts for achieving a defined step goal?

RQ3: What are country-specific user opinions and concerns on sharing activity data with health insurance and receiving rewards in return?

Our framework model (Figure 2) includes all these mentioned factors and enables the answering of the three research questions.

\section{Methods}

With our three research questions (RQ1-RQ3) in mind, an online survey was developed to generate quantitative data. The German prototype was translated into English to allow a comparison between participants from Germany and participants from the United States. We tried to keep the survey short to lose as little participants as possible, therefore aspects pictured in the research model are each represented via one or two items in the questionnaire. As we merely hope to get an overview at this point, and are planning to do further research based on this first survey, we deemed the final version consisting of 24 items as sufficient. It is structured as follows:

The heart of the questionnaire is made up out of 18 items concerning the different dimensions and factors mentioned in the research model (see Figure 2). 15 of 18 items (see appendix) are statements equipped with a seven-point Likert-type scale [18], ranging from (1) to (7), where (1) means "strongly disagree" and (7) "strongly agree". The decision to use a seven-point Likert-type scale is founded on the chosen methods of statistical analysis: Spearman-Rho correlation for identifying interrelationship and Mann-Whitney U test for country differences.

Most items are only shown to participants currently using an activity tracker. Other participants are asked for their reason(s) to discontinue usage. The questionnaire contains, apart from these items, also sociodemographical questions and background information such as: place of residence, type of activity tracker, level of fitness (1-7), level of health (1-7), gender and age. Finally, there is space for further remarks by the participants.

For the first step of our research, we only concentrate on the place of residence based on the sociodemographical and background information.

The questionnaire was pretested by nine German and English native speakers and distributed after the necessary corrections. Distribution took place mainly over social media channels (e.g. Facebook, Twitter and Reddit). On Facebook, the distribution took place mainly in fitness and activity related topic groups with different amounts of members, in both German and English language groups. As the posts in groups lose novelty rapidly, reposting was necessary. Apart from social media, the survey was distributed via mailing lists of universities and social messaging services (WhatsApp) to distribute it between individuals who use or did use an activity tracker. The participation was voluntary without any incentives and time limits. The distribution time was March 25, 2017 to June 08, 2017 and overall we reached 975 participants. After checking and cleaning the survey data, 803 participants, who successfully took part until the end of the questionnaire, were left.

\section{Results}

In the following section, the results of the survey will be presented. Overall, 674 participants were currently using an activity tracker, while 129 participants did not (anymore).

RQ1a: What strengths and weaknesses are recognized by the participants (based on perceived service quality and acceptance) concerning activity trackers?

The results of the present study (Figure 3) demonstrate that activity trackers are received very positively. Brackets include the median value. The 
perceived service quality of activity trackers is generally high. Furthermore, the participants strongly agree (7) that their trackers are easy to use and that the use of them is fun (7). Participants confirmed that their trackers are useful for the improvement of health status and their fitness level (6). Based on the prompted aspect Trust, the respondents confirm that they judge the provider of their trackers as trustworthy and do not fear the company might be abusing the tracked data $(5)$.

Fitbit enables the user to collect badges or to take part in challenges. The participants somewhat agree that these kinds of gamified elements make them feel rewarded (5). All in all, no deficits were recognized regarding the perceived service quality, as the majority of participants agreed, to varying extents to all statements. The acceptance of activity trackers (D3), was rated related to the items Impact (6) and Dissemination (7) very positively, too. Many participants confirm a positive change in their behavior, for example, being more active (take more steps, walk an extra round, and so on). Furthermore, participants felt, that using activity trackers is improving their wellbeing. Users of an activity tracker strongly agree that they would recommend the tracker to friends and other family members - indeed, a majority of our respondents seems to be convinced by the functionality of their wearables and is satisfied.

Another interesting result, not recognizable as a weakness, is the low agreement on Enforcement (1), Group Pressure (1) and Contagion (3).

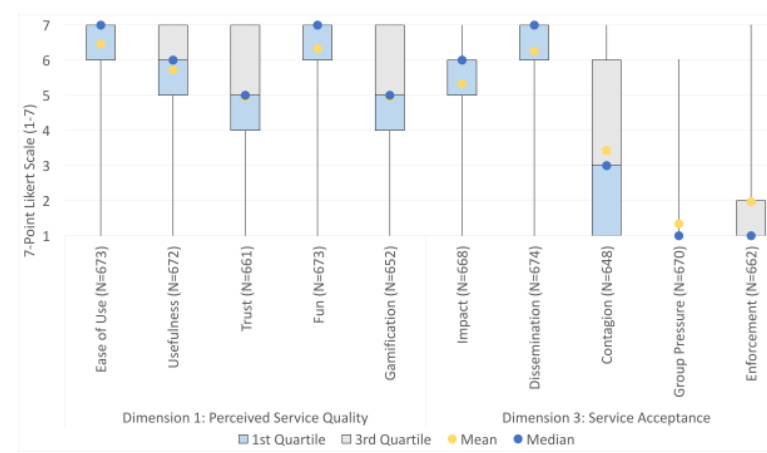

Figure 3. General agreement on perceived service quality and acceptance of activity trackers

RQ1b: How do perceived service quality and acceptance of activity trackers influence each other?

The results show that different items of the two dimensions (D1 and D3) correlate not only both, weakly and strongly, but negatively as well as positively, too (Table 1).

The item Ease of Use correlates highly significant and positively with the items Usefulness (+.297***), Trust (+.194***), Fun (+.376***), Gamification $\left(+.230^{* * *}\right)$, Impact $\left(+.295^{* * *}\right)$ and Dissemination $(+.314 * * *)$. As the values are highly significant, the strength of the correlations is rather weak. Beside this item of Dimension 1, the item Usefulness correlates more highly and positively with Fun (+.488***) and Impact $\left(+.673^{* * *}\right)$. In both cases the correlation is highly significant. Furthermore, Usefulness and Gamification positively correlate with each other $\left(+.475^{* * *}\right)$. Gamification correlates more highly and positively with the items Impact $(+.507 * * *)$, Dissemination $\left(+.441^{* * *}\right)$ and Usefulness $(+.475 * * *)$. The fact that participants trust in the provider of their activity trackers to not abuse their data, correlates positively and significantly, but weakly with the items Fun (+.218***), Gamification (+.217***), Impact $(+.254 * * *)$ and Dissemination $(+.262 * * *)$. In the last case, the correlation between Trust and Enforcement is not only very small but only lowly significant as well $\left(+.080^{*}\right)$.

It is very noticeable that the item Dissemination is the second item that has a high correlation with another item, here Impact $(+.629 * * *)$ and vice versa. Based on social aspects, Table 1 shows that there is a highly significant and weakly positive correlation between Contagion and Gamification (+.203***) and Contagion and Enforcement (+.314***). Group Pressure and Enforcement correlate positively and highly significant as well $\left(+.466^{* * *}\right)$. A negative correlation based on Table 1: Fun correlates highly significant and negatively with Group Pressure (-.219***).

RQ2: Do German participants' opinions differ from US participants', based on the agreement on perceived service quality and acceptance, regarding activity trackers?

This research question was further examined with the Mann-Whitney U test (MWU) to find out if there exists a significant difference between German and US participants related to their agreement on perceived service quality and service acceptance. The generally used statistical method for this purpose is the t-test, but this was not possible, as our data is not normally distributed. Therefore, we chose this method based on the characteristics of our data as the items are on an ordinal scale and not normally distributed. 
Table 1. Bivariate rank correlation (Spearman's rho) between perceived s ervice quality (Dimension 1), and service acceptance (Dimension 3) of activity trackers; $p<.05 * ; p<.01 * \% ;<<.001 * * *$

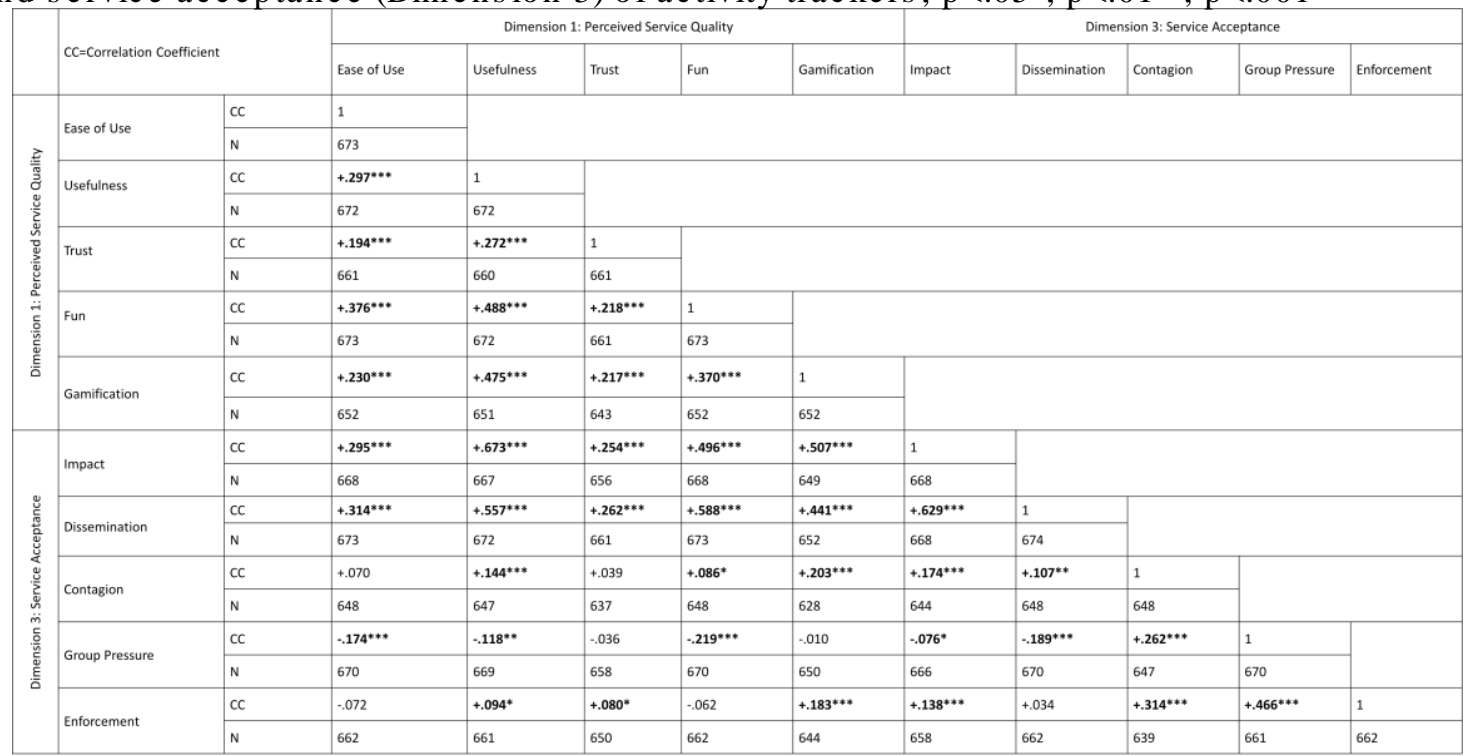

Figure 4 shows, among others, the median of the agreement on the specific items based on the countryspecific perceived service quality. Related to two items, US participants tend to agree more than German participants. While German participants somewhat agree (5), US participants agree much more (6) that they trust the provider of their activity tracker. This difference is highly significant. Even the $3^{\text {rd }}$ quartile of factor Trust is by US participants at the value of 7 the $3^{\text {rd }}$ quartile related to German participants at the value of 6 . In general, the strength of agreement differentiates on different shapes based on the 7-point Likert scale.

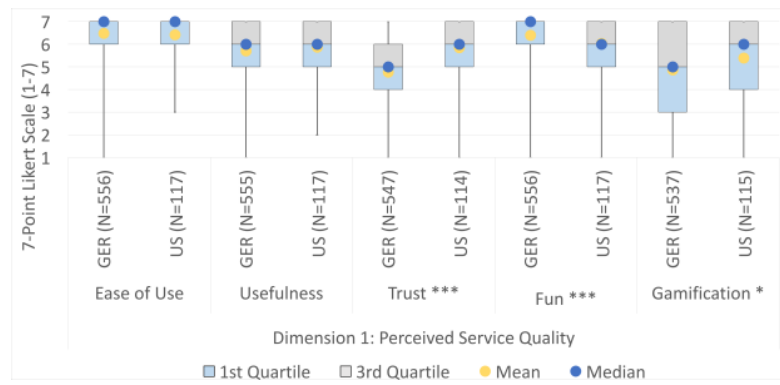

Figure 4. Country-s pecific agreements on perceived service quality and its significance $(\mathbf{p}<.05 \%, p<.01 * ;, p<.001 * *)$ according to MannWhitney $U$ test

US participants again agree a bit more (6) that they feel rewarded by functions such as the collection of badges, taking part in challenges or to improve their ranking, than German participants (5). Interestingly, the agreement related to the factor Fun differed, too. German participants tend to have more fun while using their activity tracker (7) than US participants (6).

Figure 5 shows the agreement on the specific items based on country-specific acceptance of an activity tracker. A very highly significance $(* * *)$ is recognizable with items Group Pressure and Enforcement. The country-specific differences based on Contagion is weakly significant $(*)$. Conspicuously, US and German participants totally disagree that the feel forced to use an activity tracker. But, the significant difference based on the tendency that US participants tend to disagree less $\left(3^{\text {rd }}\right.$ quartile). Interestingly, US participants tend to agree more often that they feel encouraged by their environment to use an activity tracker.

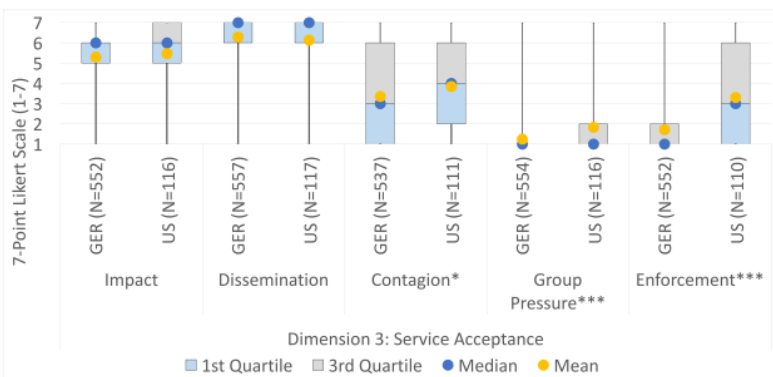

Figure 5. Country-s pecific agreements on service acceptance and its significance $(\mathbf{p}<.05 * ; p<.01 * ;, p<.001 * *)$ according to MannWhitney U test 
Table 2. Country-s pecific differences $(p<.05 * p<.01 * \%, p<.001 * * *)$ based on the agreement of getting support by health insurance funds and reducing medical fees by using activity trackers (scale: 1 (Strongly Dis agree) - 7 (Strongly Agree))

\begin{tabular}{|l|l|l|l|l|l|l|l|}
\hline \multicolumn{2}{|c|}{} & Median & $1^{\text {st }}$ Quartile & $3^{\text {rd }}$ Quartile & Mean & Std. Derivation & Sig. \\
\hline \multirow{2}{*}{$\begin{array}{l}\text { Support of Health } \\
\text { Insurance Funds }\end{array}$} & GER (N=538) & 5 & 2 & 7 & 4.4963 & 2.24334 & \multirow{2}{*}{$*$} \\
\cline { 2 - 8 } & US (N=105) & 6 & 4 & 7 & 5.0190 & 2.01905 & \\
\hline $\begin{array}{l}\text { Reduce Medical } \\
\text { Fees }\end{array}$ & GER (N=541) & 5 & 2 & 6 & 4.2921 & 2.11776 & \multirow{2}{*}{$* * *$} \\
\cline { 2 - 7 } & US (N=117) & 6 & 5 & 7 & 5.8547 & 1.35992 & \\
\hline
\end{tabular}

RQ3: What are country-specific user opinions and concerns on sharing activity data with health insurance and receiving rewards in return?

Table 2 shows that there are country-specific user differences on the agreement based on those two aspects. Especially the differences between German and US participants based on the reduction of medical fees by using an activity tracker is highly significant. German participants do not hope to save medical expenses in the present or future as much as US participants. The differences based on the agreement that health insurance funds should support users with tracked activities, are also significant. US users disagree less than German users and tend to agree with support from health insurance funds more in some cases.

\section{Discussion}

We presented an exploratory study regarding the adoption, impact, use and diffusion of activity trackers. We also identified issues, as the participation of health insurance funds, as well as country-specific differences. As previous findings are mostly based on a small size of participants or on qualitative interviews, a quantitative study, using an online questionnaire, was pursued.

Activity trackers have become an interesting research subject and the use as well as the effects of this novel information system should be investigated thoroughly. Our study serves as another window to an understanding of the processes surrounding activity trackers. As the results show the simplicity of a system (here the use of the activity tracker) supports other aspects of the perceived service quality but also the acceptance of a service. A system that is easy to use and fun makes it easier to become more fit and healthy. Based on the results we could sum up that the more the service is perceived as easy to use, the more people get fun to use it and the more people disseminate the service to friends and families. Their willingness to disseminate activity trackers is assured by the perceived impact, too. The more people recognize that the activity tracker changes their behavior in a positive way, the more they will recommend the service to friends and family members.
Especially for people who are not used to having a regular fitness schedule, actigraphs are used to support and facilitate the formation of new habits. In some cases, users need to be challenged to keep motivated. Feeling motivated is closely related to gamification. Gamification elements, such as rewards, challenges and rankings, are tools of motivation themselves but also an additional reason to invite friends to take part. On the other side, especially, if friends or family members are talking positively and excited about challenges and goals, the wish to take part oneself becomes stronger.

New and successfully tackled challenges are fun and could improve self-awareness. Otherwise, people might lose interest in using their tracker, if they do not feel entertained or challenged. In the questionnaire, 5 users reported this as well. Other reasons for the discontinuance ("Opting-Out") of using activity trackers are faulty or damaged hardware (mentioned 10 times in the survey) and trackers that needed to be charged far too often (mentioned 7 times) or that were too expensive (6 times). 4 participants simply stopped tracking because the wristband felt uncomfortable while sleeping or working.

As activity trackers are said to enable the possibility to change behavior and improve wellbeing, it is necessary to test whether this is really true. If someone buys an activity tracker, and does not recognize any changes, then there could be two possible failure sources: The functionalities of the device missed or the user does not really use it as intended. Our results show, however, that our participants recognize their devices as useful and confirm an improvement of fitness level and health status. Additionally, the correlations of RQ1b shows that the more participants realize an improvement of their own health and fitness, the more they are having fun using the tracker and reverse.

In today's world, collecting all kinds of data via ICT is a given and has become a task of high importance for many institutions. But besides the fear of data abuse based on other services, the participants of this study do not mistrust providers in this area. In contrary, they somewhat agree that medical funds should support and reward the process of becoming more active by getting access to tracked data. In Germany, there are some medical funds who already give rewards if you buy an 
activity tracker or track steps with an app [3]. Furthermore, the use of services can also depend on the social environment, as one would assume. But this research shows that most users are not being motivated by group pressure.

All in all, there are a lot of positive and highly significant correlations in the areas we examined. We can already see that the success of managing and improving personal health and fitness levels by using activity trackers is intermeshed with different aspects. If I recognize advantages by feeling better or by changing my behavior in a positive way, I also am more motivated to keep going on and reversed. Gamification may be seen to motivate a positive change in perceptions about usefulness and impact. This may indicate that people who feel rewarded by badges and rankings may also view the technology as useful and beneficial. Or if I really change my behavior, a typical example, I choose the stairs and not the elevator, I will recognize advantages in turn - so the device is used for improving user's fitness level and health status. And in the end, it is undeniable that all these positive aspects influence the willingness to disseminate activity trackers. Why should satisfied and motivated people not recommend their activity tracker?

Besides the mentioned positive correlations there exist negative correlations, too. Dissemination correlates weak but negatively highly significant with Group Pressure. Group Pressure may be seen as demotivation. Nevertheless, in combination with the item Enforcement it is recognizable that the more people notice that friends or colleagues are taking part in challenges together, the more people feel the wish to use an activity tracker, too. This seems paradoxical but could indicate that users' perception conflates between enforcement and group pressure sometimes. Especially because often communities at work or school are also social groups capable of applying group pressure.

Besides, effects or agreement based on different aspect could be country-specific. This could lead to different developments in the mentioned area of health insurance, depending on culture and other sociodemographical backgrounds. Therefore, the results show that US participants agreed more on reducing medical fees by using activity trackers. The reason for this result could be the different medical care systems. This opens up a new area of research, not only health information systems could improve or support the management of health insurance in any way, but the integration of medical funds or the integration of the medical care system could change completely. Another question is connected to the different kinds of 'Group Pressure': Is this really not an issue or are users simply not aware or not willing to admit being influenced by others? In our case, US participants tend to disagree less than German users, related to enforcement and contagion. For one example, in the United States, Oral Roberts University in Tulsa requires their students to buy and use an activity tracker.

Clearly, some propositions offered by the collected data are not entirely unique as the results given above prove that some aspects of the previous research are confirmed by many participants. However, we submit that the contribution of our paper rests on two relatively new areas: country-specific characteristics and external factors such as medical funds and the possibility to reduce medical fees. In the future, we want to try to get more American and international participants, as it seems that there is another perception of using and integrating activity trackers.

What is the right way to improve wellbeing, fitness and health? Should we start wearing actigraphs in preschools, schools and universities to educate pupils and to develop an awareness on how to improve health and fitness level?

Previous studies show that interviews with users allow a deeper understanding of the circumstances and could help to identify problems and the potential of subjective feelings of wellbeing.

Our research has some limitations. We feel that our study emphasizes the need for more in-depth research on aspects that are going beyond the questions of this study. There is much more research potential if we concentrate on external and social-demographic aspects. Furthermore, a comparison between completely different cultural backgrounds, for example, Asian countries and Western countries, could be interesting, too.

Based on the aspect of external factors, such as medical healthcare funds and the reduction of medical cost, in-depth surveys and interviews would be the next step in the future, also to compare the perception of medical healthcare funds and activity tracker users based on this topic. Furthermore, our empirical data represent different age groups. Therefore, another future project could be the analysis of differences between different generations (Baby boomers, Generation X, Generation Y, Generation Z) [19].

Finally, potential future research based on this data could also be the fitness level and health status background. Users that are not healthy could probably be more motivated by the support of medical healthcare funds than very active people. 


\section{Appendix}

\begin{tabular}{|c|c|c|c|c|}
\hline Item & & Item & $\begin{array}{c}\text { 7-Point } \\
\text { Likert Scale }\end{array}$ & Question/Indicator \\
\hline 1 & & & & Please select your place of residence: \\
\hline 2 & & & & Do you currently use an activity tracker? \\
\hline 3 & & & $\mathrm{x}$ & $\begin{array}{l}\text { By sharing fitness activities with my health insurance (documented by my } \\
\text { activity tracker) I should be eligible for finical support, for example by } \\
\text { lowering health insurance contributions. }\end{array}$ \\
\hline 4 & & & $\mathrm{x}$ & $\begin{array}{l}\text { By being active I hope to save medical expenses in the present or future } \\
\text { (for medicine or medical treatment). }\end{array}$ \\
\hline 5 & \multirow{6}{*}{ 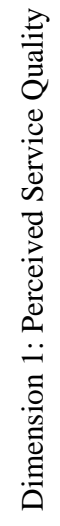 } & Ease of Use & $\mathrm{x}$ & My activity tracker is easy to use. \\
\hline 6 & & \multirow{2}{*}{ Usefulness } & $\mathrm{x}$ & My activity tracker is useful for the improvement of my fitness level. \\
\hline 7 & & & $\mathrm{x}$ & My activity tracker is useful for the improvement of my health status. \\
\hline 8 & & Trust & $\mathrm{x}$ & $\begin{array}{l}\text { I am trusting the provider of my activity tracker to refrain from abusing my } \\
\text { data in any way. }\end{array}$ \\
\hline 9 & & Fun & $\mathrm{x}$ & It is fun to use my activity tracker. \\
\hline 10 & & Gamification & $\mathrm{x}$ & $\begin{array}{l}\text { I feel rewarded by functions such as the collection of badges, taking part in } \\
\text { challenges or to check my ranking. }\end{array}$ \\
\hline 11 & \multirow{7}{*}{ 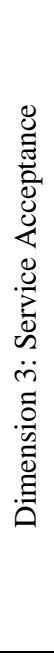 } & \multirow{3}{*}{ Impact } & $\mathrm{x}$ & Ever since I am using my activity tracker, I am feeling better. \\
\hline 12 & & & $\mathrm{x}$ & $\begin{array}{l}\text { Ever since I am using my activity tracker, I absolutely do not want to } \\
\text { abstain from using it. }\end{array}$ \\
\hline 13 & & & $\mathrm{x}$ & $\begin{array}{l}\text { My activity tracker changed my behavior (I take the stairs more often or go } \\
\text { an extra round). }\end{array}$ \\
\hline 14 & & Dissemination & $\mathrm{x}$ & I would recommend the activity tracker to others. \\
\hline 15 & & Contagion & $\mathrm{x}$ & $\begin{array}{l}\text { Friends, family members or colleagues had an activity tracker. Somehow it } \\
\text { was contagious and I bought an activity tracker, too. }\end{array}$ \\
\hline 16 & & Group Pressure & $\mathrm{x}$ & $\begin{array}{l}\text { I feel forced to use an activity tracker by people in my environment } \\
\text { (e.g. school class, colleagues, family members). }\end{array}$ \\
\hline 17 & & Enforcement & $\mathrm{x}$ & $\begin{array}{l}\text { During school, university or on the job I feel encouraged to use an activity } \\
\text { tracker. For example, to go take part in competitions or activities (such as } \\
\text { collecting steps together during break). }\end{array}$ \\
\hline 18 & & & & Why are you currently not using an activity tracker? \\
\hline
\end{tabular}

\section{References}

[1] R.M. Alturki, and V. Gay, "A Systematic Review on What Features Should Be Supported by Fitness Apps and Wearables to Help Users Overcome Obesity", International Journal of Research in Engineering and Technology, 5(9), 2016, pp. 197-206.

[2] G. Angulo, D. Brogan, A. Martini, J. Wang, and L.A.
Clevenger, "Health Features of Activity Trackers : Motivation, Goal Achievement, and Usability", in The Conference Proceeding of the Michael L. Gargano $14^{\text {th }}$ Annual Research Day (6st May 2016), Seidenberg School of CSIS, Pace University , 2016, pp. A5-1-A5-8.

[3] AOK PLUS, AOK Bonus-APP, Online: https://plus.aok.de/inhalt/aok-bonus-app/.

[4] S.A. Brown, and V. Venkatesh, "Model of Adoption of Technology in Households: A Baseline Model Test and 
Extension Incorporating Household Life Cycle", MIS Quarterly, 29(3), 2005, pp. 399-426.

[5] J. Clawson, J.A. Pater, A.D. Miller, E.D. Mynatt, and L. Mamykina, "No Longer Wearing: Investigating the Abandonment of Personal Health-Tracking Technologies on Craigslist", in Proceedings of the 2015 ACM International Joint Conference on Pervasive and Ubiquitous Computing (September 07-11), ACM, NY, USA, 2015, pp. 647-658.

[6] F.D. Davis, "Perceived Usefulness, Perceived Ease of Use, and User Acceptance of Information Technology", MIS Quarterly, 13(3), 1989, pp. 319-340.

[7] S. Day, "Self-tracking Over Time: The FITBIT® Phenomenon", in The $7^{\text {th }}$ Annual Conference of Computing and Information Technology Research and Education New Zealand (CITRENZ2016) and the 29 $9^{\text {th }}$ Annual Conference of the National Advisory Committee on Computing Qualifications, Wellington, New Zealand (July 11-13), 2016, pp. 1-6.

[8] S. Deterding, D. Dixon, R. Khaled, and L. Nacke, "From Game Design Elements to Gamefulness: Defining 'Gamification'", in Proceedings of the $15^{\text {th }}$ International Academic MindTrek Conference: Envisioning Future Media Environments (September 28-30), ACM, NY, USA, 2011, pp. $9-15$.

[9] T. Fritz, E.M. Huang, G.C. Murphy, and T. Zimmermann, "Persuasive Technology in the Real World: A Study of LongTerm Use of Activity Sensing Devices for Fitness", in Proceedings of the SIGCHI Conference on Human Factors in Computing Systems (April 26 - May 01), ACM, NY, USA, 2014, pp. 487-496.

[10] IDC, Worldwide Wearables Market Increases $67.2 \%$ Amid Seasonal Retrenchment, According to IDC, 2017, Online:

http://www.idc.com/getdoc.jsp?containerId=prUS41284516.

[11] Y. Gao, H. Li, and Y. Luo, "An Empirical Study of Wearable Technology Acceptance in Healthcare", Industrial Management \& Data Systems, 115(9), 2015, pp. 1704-1723. [12] D. Gefen, E. Karahanna, and D.W. Straub, "Trust and TAM in Online Shopping: An Integrated Model", MIS Quarterly, 27(1), 2003, pp. 51-90.

[13] L. Giddens, D. Leidner, and E. Gonzalez, "The Role of Fitbits in Corporate Wellness Programs: Does Step Count Matter?" in Proceedings of the 50 $0^{\text {th }}$ Hawaii International Conference on System Sciences (January, 04-07), IEEE Computer Society, Washington D.C., 2017, pp. 3627-3635.

[14] K. Kawamoto, T. Tanaka, and H. Kuriyama, "Your Activity Tracker Knows When You Quit Smoking", in Proceedings of the 2014 ACM International Symposium on Wearable Computers (September 13-17), ACM, NY, USA, 2014, pp. 107-110.

[15] Leard Statistics, "Cronbach's Alpha", Online: https://statistics.laerd.com/premium/spss/ca/cronbachs-alphain-spss.php

[16] D. Ledger, and D. McCaffrey, "Inside Wearables. How the Science of Human Behavior Change Offers the Secret to Long-Term Engagement", in LCC EP, D. Ledger, and D. McCarey (eds.), Endeavour Partners, Cambridge, MA, 2014, pp. 1-17.

[17] I. Li, A. Dey, and J. Forlizzi, "A Stage-Based Model of Personal Informatics Systems", in Proceedings of the SIGCHI Conference on Human Factors in Computing Systems (April
10-15), ACM, NY, USA, 2010, pp. 557-566.

[18] R. Likert, "A Technique for the Measurement of Attitudes", Archives of Psychology, 140, 1932.

[19] E. Lins, K.J. Fietkiewicz, and E. Lutz, "How to Convince the Crowd: An Impression Management Approach", in Proceedings of the Annual Hawaii International Conference on System Sciences (January 5-8), IEEE Computer Society, Washington D.C., 2016, pp. 3505-3514.

[20] S.E. Schaefer, C.C. Ching, H. Breen, and J.B. German, "Wearing, Thinking, and Moving: Testing the Feasibility of Fitness Tracking with Urban Youth", American Journal of Health Education, 47(1), 2016, pp. 8-16.

[21] L. Schumann, and W.G. Stock, "The Information Service Evaluation (ISE) Model", Webology, 11(1), 2014, pp. 1-20.

[22] P.C. Shih, K. Han, E.S. Poole, M.B. Rosson, and J.M. Carroll, "Use and Adoption Challenges of Wearable Activity Trackers", in Proceedings of the iConference 2015 (March 2427), iSchools, IDEALS, University of Illinois at UrbanaChampaign, 2015, pp. 1-12.

[23] G. Shin, E.J. Cheon, and M.H. Jarrahi, "Understanding Quantified-Selfers' Interplay between Intrinsic and Extrinsic Motivation in the Use of Activity-Tracking Devices", in Proceedings of the iConference 2015 (March 24-27), iSchools, IDEALS, University of Illinois at UrbanaChampaign, 2015, pp. 1-3.

[24] O. Turel, A. Serenko, and P. Giles, "Integrating Technology Addiction and Use: An Empirical Investigation of Online Auction Users", MIS Quarterly, 35(4), 2011, pp. 10431061.

[25] University Oral Roberts, Oral Roberts University Integrates Wearable Technology With Physical Fitness Curriculum for Incoming Students, 2016, Online: http://www.oru.edu/news/oru_news/20160104_fitbit_trackin g.php.

[26] V. Venkatesh, "Determinants of Perceived Ease of Use: Integrating Control, Intrinsic Motivation and Emotion into the Technology Acceptance Model", Information Systems Research, 11(4), 2000, pp. 342-365.

[27] V. Venkatesh, and F.D. Davis, "A Theoretical Extension of the Technology Acceptance Model: Four Longitudinal Field Studies", Management Science, 46(2), 2000, pp. 186204.

[28] V. Venkatesh, M.G. Morris, G.B. Davis, and F.D. Davis, "User Acceptance of Information Technology: Toward a Unified View", MIS Quarterly, 27(3), 2003, pp. 425-478.

[29] J. Wylie, Fitness Gamification: Concept, Characteristics, and Applications, 2010, Online: http://www.justintwylie.com/wp-

content/uploads/2014/12/JUSTIN-WYLIE-Fitness-

Gamification.pdf 